\title{
Seletividade de Herbicidas Aplicados em Pré-Emergência em GRAMÍnEAS FORRAGEIRAS ${ }^{1}$
}

\author{
Selectivity of Pre-Emergence Herbicides Applied on Forage Grasses \\ RODRIGUES-COSTA, A.C.P. ${ }^{2}$, MARTINS, D. ${ }^{3}$, COSTA, N.V. ${ }^{4}$, CAMPOS, C.F. ${ }^{5}$, MARTINS, C.C. ${ }^{3}$, \\ PEREIRA, M.R.R. ${ }^{5}$ e SILVA, J.I.C. ${ }^{5}$
}

\begin{abstract}
RESUMO - O presente trabalho teve o objetivo de avaliar a seletividade de herbicidas aplicados em pré-emergência sobre a produção e a qualidade de sementes de Brachiaria brizantha cv. Marandu e Brachiaria decumbens cv. Basilisk. Os herbicidas avaliados foram: diuron (800 e $\left.1.600 \mathrm{~g} \mathrm{ha}^{-1}\right)$, ametryn (625 e $\left.1.250 \mathrm{~g} \mathrm{ha}^{-1}\right)$, imazaquin (75 e $150 \mathrm{~g} \mathrm{ha}^{-1}$ ), imazethapyr (50 e $100 \mathrm{~g} \mathrm{ha}^{-1}$ ) e flumetsulam (70 e $140 \mathrm{~g} \mathrm{ha}^{-1}$ ), além de uma testemunha sem aplicação de herbicidas. As espécies foram avaliadas separadamente no campo. Os experimentos foram instalados no delineamento em blocos casualizados com quatro repetições. Os herbicidas

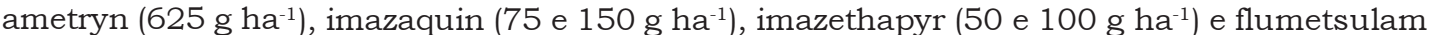
(70 e $140 \mathrm{~g} \mathrm{ha}^{-1}$ ) foram os que proporcionaram maior seletividade às plantas de B. brizantha, enquanto para $B$. decumbens o diuron (800 e $\left.1.600 \mathrm{~g} \mathrm{ha}^{-1}\right)$, o ametryn (625 e $\left.1.250 \mathrm{~g} \mathrm{ha}^{-1}\right)$ e o imazethapyr (50 e $100 \mathrm{~g} \mathrm{ha}^{-1}$ ) foram mais seletivos, destacando-se o diuron na menor dose. Contudo, os herbicidas avaliados não alteram a produção e a qualidade das sementes das forrageiras estudadas.
\end{abstract}

Palavras-chave: Brachiaria brizantha, Brachiaria decumbens, pastagem, germinação.

\begin{abstract}
This study aimed to evaluate the selectivity of pre-emergence herbicides on yield and seed quality of Brachiaria brizantha $c v$. Brizantha and Brachiaria decumbens $c v$. Basilisk. The herbicides evaluated were: diuron (800 and $1.600 \mathrm{~g} \mathrm{ha}^{-1}$ ), ametryn (625 and $1.250 \mathrm{~g} \mathrm{ha}^{-1}$ ), imazaquin (75 and $150 \mathrm{~g} \mathrm{ha}^{-1}$ ), imazethapyr (50 and $100 \mathrm{~g} \mathrm{ha}^{-1}$ ) and flumetsulam (70 and $140 \mathrm{~g} \mathrm{ha}$ ), plus a control without herbicide application. The species were evaluated separately in the field. The experiments were arranged in a randomized block design with four replications. The herbicides ametryn (625 $\mathrm{g} \mathrm{ha}^{-1}$ ), imazaquin (75 and $150 \mathrm{~g} \mathrm{ha}^{-1}$ ), imazethapyr (50 and $100 \mathrm{~g} \mathrm{ha}^{-1}$ ), and flumetsulam $\left(70\right.$ and $\left.140 \mathrm{~g} \mathrm{ha}^{-1}\right)$ provided the highest selectivity to $\boldsymbol{B}$. brizantha plants, while for $\boldsymbol{B}$. decumbens, diuron (800 and $1.600 \mathrm{~g} \mathrm{ha}^{-1}$ ), ametryn (625 and $1.250 \mathrm{~g} \mathrm{ha}^{-1}$ ), and imazethapyr (50 and $100 \mathrm{~g} \mathrm{ha}^{-1}$ ) were more selective, especially diuron, at the lowest dose. However, the tested herbicides do not affect the yield and quality of the seeds of the forage grasses studied.
\end{abstract}

Keywords: Brachiaria brizantha, Brachiaria decumbens, pasture, germination.

\section{INTRODUÇÃO}

A produção de sementes forrageiras, visando atender à demanda para formação e / ou reforma de pastagens e formação de palha para consolidação do sistema de plantio direto, está gradativamente alcançando niveis tecnológicos adequados e coerentes com a importância da atividade (Pereira et al., 2000; Jakelaitis et al., 2004; Borghi et al., 2008, Pellegrini et al., 2010). Contudo, ainda é muito frequente o uso de sementes de má qualidade,

Recebido para publicação em 8.9.2010 e aprovado em 14.2.2011

2 Bolsista Pós-Doutorado, Universidade Estadual do Oeste do Paraná - CCA/UNIOESTE, Caixa Postal 91, 85960-000 Marechal Cândido Rondon-PR, <andreiacpr@hotmail.com>; ${ }^{3}$ Professor Adjunto, Dep. de Produção Vegetal, FCA/UNESP, Fazenda Lageado, Caixa Postal 237, 18603-970 Botucatu-SP; ${ }^{4}$ Professor Adjunto, CCA/UNIOESTE, campus de Marechal Cândido Rondon-PR; ${ }^{5}$ Alunos de Pós-Graduação, Dep. de Produção Vegetal, FCA/UNESP, Botucatu-SP. 
principalmente no que se refere à baixa pureza e ao baixo potencial de germinação. Devido aos diferentes processos de colheita e às diversas origens das sementes utilizadas, é comum encontrar sementes com excesso de resíduos vegetais, solo ou, ainda, mistura de sementes de outras forrageiras ou de plantas daninhas.

A infestação das pastagens está relacionada à grande agressividade que as plantas daninhas apresentam, bem como à degradação da forrageira por manejo inadequado ou, ainda, por implantação inicial inadequada (Alves et al., 2002).

Segundo Martins et al. (2007), a estratégia mais eficiente para evitar os problemas e as perdas de sementes das forrageiras no processo de beneficiamento consiste em manter a área de produção de sementes livre de plantas daninhas. Durante a fase de estabelecimento, essas plantas competem com a pastagem, reduzindo o rendimento de sementes e, provavelmente, contaminando os lotes durante a colheita, o que pode ser verificado na análise de pureza e exame de sementes nocivas.

A aplicação de herbicidas pode minimizar a interferência das plantas daninhas em áreas de pastagens e reduzir o banco de sementes do solo dessas espécies (Fortunato Júnior et al., 2007; Pellegrini et al., 2007). Vários herbicidas foram introduzidos no mercado nacional nas duas últimas décadas, o que aumentou a possibilidade de eliminação seletiva de plantas indesejáveis em diversas culturas. No entanto, possiveis efeitos de fitointoxicação por esses produtos ainda não foram avaliados de forma satisfatória para as gramíneas forrageiras tropicais de interesse comercial no Brasil, o que limita seu uso nos campos de produção de sementes e em áreas de pastagens (Alves et al., 2002; Martins et al., 2007).

Loch \& Harvey (1997), em estudos realizados na Austrália, indicaram os herbicidas atrazine, simazine, metribuzin, metsulfuronmethyl e chlorsulfuron promitentes quanto à seletividade para gramineas forrageiras. Contudo, a seleção do herbicida e da dose a ser utilizada depende da espécie (Ferri et al., 2001). No Brasil, ainda não foi avaliado o grau de seletividade de vários herbicidas para produção e qualidade de sementes em espécies relevantes.
São escassas as informações disponiveis na literatura referentes ao grau de seletividade de herbicidas no controle de plantas daninhas em pastagens e na avaliação de eventuais efeitos desses produtos na produção de sementes pelas gramineas forrageiras.

O objetivo deste trabalho foi avaliar a seletividade de herbicidas pré-emergentes na produção e na qualidade de sementes de Brachiaria brizantha cv. Marandu e $B$. decumbens cv. Basilisk em campo.

\section{MATERIAL E MÉTODOS}

O presente trabalho foi instalado e conduzido em campo, na Fazenda Experimental Lageado, da Faculdade de Ciências Agronômicas - FCA/UNESP, campus de Botucatu/ SP, no ano agrícola de 2007/2008. O local possui as seguintes coordenadas geográficas: latitude de $22^{\circ} 07^{\prime} 56^{\prime \prime}$ S e longitude de $74^{\circ} 66^{\prime} 84^{\prime \prime}$ WGr, com altitude média de $762 \mathrm{~m}$.

O preparo do solo foi realizado mecanicamente, por meio de uma aração com arado de aiveca, gradagem com uma grade pesada e duas operações de grade niveladora. No preparo do solo, realizou-se a calagem em área total, aplicando-se $100 \mathrm{~kg} \mathrm{ha}^{-1}$ de calcário dolomítico para atingir o $\mathrm{V} \%$ igual a 70. A análise química evidenciou $\mathrm{pH}$ em $\mathrm{CaCl}_{2}$ de 5,4; teor de matéria orgânica de $29,0 \mathrm{~g} \mathrm{dm}^{-3}$; CTC de 91,0 e $\mathrm{P}$ de $60,0 \mathrm{mg} \mathrm{dm}^{-3}$; valores de 2,5, 39,0 e 22,0 mmolc $\mathrm{dm}^{-3}$ para $\mathrm{K}$, Ca e $\mathrm{Mg}$, respectivamente; e saturação por bases de $63,5 \%$. As características físicas do solo utilizado eram: 749, 52 e $199 \mathrm{~g} \mathrm{~kg}^{-1}$ de areia, silte e argila, respectivamente. A adubação da área foi realizada com base na recomendação para forrageiras (Raij et al., 1997).

Foram avaliadas as gramíneas forrageiras Brachiaria brizantha cv. Marandu e Brachiaria decumbens cv. Basilisk. As forrageiras foram avaliadas separadamente. O delineamento experimental foi em blocos casualizados, com quatro repetições.

As parcelas experimentais continham três linhas de semeadura com $5 \mathrm{~m}$ de comprimento, espaçadas de $1,5 \mathrm{~m}$ entre si, totalizando $22,5 \mathrm{~m}^{2}$. A semeadura foi realizada no dia 27/10/2007. A densidade de semeadura foi baseada no valor cultural (VC) do lote, que para 
B. brizantha foi de $70 \%$, e a germinação, de $80 \%$, enquanto para a $B$. decumbens o VC foi de $70 \%$ e a germinação de $90 \%$. As sementes foram distribuídas manualmente no sulco de semeadura, em quantidade necessária para alcançar 20 plântulas $\mathrm{m}^{-1}$.

Após a emergência das plântulas foi feito o desbaste manual, para atingir o estande final de 15 plantas $\mathrm{m}^{-1}$ das forrageiras. Foram realizadas três capinas manuais, para manutenção das parcelas livres da interferência das plantas daninhas durante o período experimental.

Os tratamentos consistiram na aplicação dos herbicidas pré-emergentes diuron $(800$ e $\left.1.600 \mathrm{~g} \mathrm{ha}^{-1}\right)$, ametryn (625 e $1.250 \mathrm{~g} \mathrm{ha}^{-1}$ ), imazaquin (75 e $150 \mathrm{~g} \mathrm{ha}^{-1}$ ), imazethapyr (50 e $100 \mathrm{~g} \mathrm{ha}^{-1}$ ), flumetsulam (70 e $140 \mathrm{~g} \mathrm{ha}^{-1}$ ), além de uma testemunha sem aplicação de herbicida. A aplicação foi realizada no dia seguinte à semeadura. Foi utilizado um pulverizador costal, pressurizado a $\mathrm{CO}_{2}$, equipado com uma barra de pulverização munida com seis pontas de jato plano tipo Teejet XR 11002 VS. A pressão de trabalho foi de $200 \mathrm{kPa}$, com consumo de calda de $200 \mathrm{~L} \mathrm{ha}^{-1}$. As médias de temperatura, umidade relativa do ar e velocidade do vento no momento da aplicação foram de $26,1^{\circ} \mathrm{C}, 63,5 \%$ e $0,5 \mathrm{~m} \mathrm{~s}^{-1}$, respectivamente.

Os efeitos de fitointoxicação dos herbicidas sobre as plantas de $B$. brizantha e $B$. decumbens foram avaliados aos 15, 30, $45 \mathrm{e}$ 60 dias após aplicação (DAA), de acordo com uma escala percentual e visual de notas de 0 a 100, na qual 0 consistiu em ausência de injúria e 100 em morte das plantas (SBCPD, 1995). Aos 45 DAA, foram coletadas as plantas presentes em 0,5 $\mathrm{m}$ da linha central de cada parcela, as quais foram secas em estufa de ventilação forçada de ar a $60{ }^{\circ} \mathrm{C}$, até atingirem peso constante; em seguida, foi determinado o acúmulo de massa seca das forrageiras ( $\mathrm{g}$ por planta).

Com a finalidade de avaliar o efeito dos tratamentos no porte das plantas, foram feitas medições de altura aos 30, 45, 60 e 90 DAA. As avaliações de altura das plantas foram realizadas medindo-se por meio de uma trena graduada, da base da planta a partir do solo até o ápice da folha mais alta, posicionada de forma ereta manualmente.
A colheita das sementes foi realizada 248 dias depois da emergência das forrageiras, após a degrana natural total das panículas das plantas das forrageiras. Com o uso de uma roçadeira costal motorizada, foi realizado o corte das plantas rente ao solo, seguida da remoção da palhada. Posteriormente, foi realizada a varredura das sementes depositadas em uma área útil de coleta de $12 \mathrm{~m}^{2}$ no centro de cada parcela. A varredura foi feita de forma superficial, com a retirada de uma camada uniforme de $0,5 \mathrm{~cm}$ de solo, o que foi suficiente para o aproveitamento máximo das sementes enterradas. No campo, foi realizada uma pré-limpeza das sementes colhidas, por meio de peneiração manual, com eliminação de palha e torrões.

As amostras provenientes da pré-limpeza realizada ainda no campo foram colocadas em sacos de papel e levadas ao laboratório para serem pesadas. Posteriormente, as amostras foram levadas à câmera seca $\left(16^{\circ} \mathrm{C}\right.$ e $35-45 \%$ UR), a fim de serem armazenadas até $o$ beneficiamento.

As amostras de cada parcela foram encaminhadas à mesa gravitacional, ajustada de maneira a permitir maior separação de materiais indesejáveis (sementes sem pergaminho, partículas de solo, restos de plantas, glumas vazias e outros), utilizando-se lixa 180. Em seguida, os materiais indesejáveis das amostras dessa primeira etapa do beneficiamento foram novamente separados, utilizando-se lixa 400. As amostras obtidas foram homogeneizadas com auxílio de um divisor de solos, para obtenção de amostras e determinação da produção de sementes puras $\left(\mathrm{kg} \mathrm{ha}^{-1}\right)$, conforme metodologia proposta em Brasil (1992).

Para cada forrageira foi realizado em laboratório teste de germinação, utilizando-se a porção de sementes puras, obtidas após o teste de pureza, sem a aplicação de nenhum processo de superação de dormência. O teste de germinação foi instalado no delineamento inteiramente casualizado; de cada parcela foram obtidas quatro subamostras, totalizando 16 repetições de 50 sementes por tratamento.

As sementes foram colocadas sobre duas folhas de papel-filtro, umedecidas com água destilada na proporção de 2,5 vezes seu peso

Planta Daninha, Viçosa-MG, v. 29, n. 3, p. 625-633, 2011 
seco (Brasil, 1992), em caixas plásticas transparentes, tipo gerbox. O conjunto foi colocado individualmente em saco plástico de $0,05 \mathrm{~mm}$ de espessura para a manutenção da umidade do substrato (Gaspar et al., 2003). A primeira e a segunda contagem de germinação foram realizadas aos sete e 28 dias após a instalação do teste, respectivamente. Os parâmetros de avaliação foram: porcentagem de plântulas normais, de plântulas anormais, de sementes mortas e de sementes dormentes.

Para verificar a viabilidade das sementes remanescentes na contagem final do teste de germinação, foi realizado o teste de tetrazólio, classificando-se as sementes em vivas e mortas, conforme metodologia proposta por Dias \& Alves (2001).

Os resultados foram submetidos à análise de variância pelo teste $\mathrm{F}$, e as médias dos tratamentos, comparadas pelo teste t a $5 \%$ de probabilidade, com auxílio do programa estatístico SISVAR.

\section{RESULTADOS E DISCUSSÃO}

Na Tabela 1 são apresentadas as médias de porcentagem de fitointoxicação de $B$. brizantha após a aplicação de herbicidas pré-emergentes. Observou-se que, aos 15 DAA, as plantas de $B$. brizantha apresentaram sintomas de intoxicação promovidos por todos os herbicidas avaliados; o diuron, o ametryn e o flumetsulam, nas maiores doses, foram menos seletivos, ao passo que, quando foram utilizadas as menores doses, a seletividade foi intermediária. Da mesma forma, o imazaquin e o imazethapyr foram mais seletivos nas menores doses, com médias de fitointoxicação inferiores a $19 \%$.

Aos 30 DAA, as plantas apresentaram leve redução dos sintomas de injúrias, sendo que os herbicidas diuron, ametryn e flumetsulam, nas maiores doses, promoveram sintomas de intoxicação superiores a 40\%, aos 45 DAA. Aos 60 DAA, apenas o diuron (800 e $\left.1.600 \mathrm{~g} \mathrm{ha}^{-1}\right)$, o ametryn ( $\left.1.250 \mathrm{~g} \mathrm{ha}^{-1}\right)$ e o flumetsulam (140 $\mathrm{g} \mathrm{ha}^{-1}$ ) diferiram da testemunha sem aplicação. Da mesma forma, verificou-se que, apesar dos elevados sintomas iniciais, os herbicidas ametryn (625 $\left.\mathrm{g} \mathrm{ha}^{-1}\right)$, imazaquin (75 e $\left.150 \mathrm{~g} \mathrm{ha}^{-1}\right)$, imazethapyr (50 $\left.\mathrm{g} \mathrm{ha}^{-1}\right) \mathrm{e}$ flumetsulam $\left(70 \mathrm{~g} \mathrm{ha}^{-1}\right)$ promoveram sintomas de fitointoxicação inferiores a $16 \%$, aos 60 DAA, demonstrando a retomada do desenvolvimento das plantas.

Na Tabela 2 podem ser observadas as médias de altura e de produção de massa seca das plantas de $B$. brizantha após a aplicação dos herbicidas pré-emergentes. Notou-se que os herbicidas promoveram redução na altura das plantas até 60 DAA, com exceção do imazethapyr (50 $\left.\mathrm{g} \mathrm{ha}^{-1}\right)$ e do flumetsulam (70 $\left.\mathrm{g} \mathrm{ha}^{-1}\right)$. Contudo, aos 90 DAA, com exceção do diuron (1600 $\mathrm{g} \mathrm{ha}^{-1}$ ), os tratamentos não diferiram da testemunha.

Observou-se que as plantas, mesmo apresentando elevados niveis iniciais de injúrias (Tabela 1), não tiveram o acúmulo de massa seca comprometido aos 45 DAA, com exceção do herbicida flumetsulam (140 $\mathrm{g} \mathrm{ha}^{-1}$ ), que mostrou redução em torno de $50 \%$ em relação à testemunha sem aplicação (Tabela 2).

Os resultados obtidos para os herbicidas ametryn, imazethapyr e flumetsulam na menor dose e imazaquim nas duas doses testadas corroboram os encontrados por Alves et al. (2002), que avaliaram os herbicidas diuron $\left(800 \mathrm{~g} \mathrm{ha}^{-1}\right)$, ametryn (625 e $\left.1.250 \mathrm{~g} \mathrm{ha}^{-1}\right)$, imazaquin (75 e $150 \mathrm{~g} \mathrm{ha}^{-1}$ ), imazethapyr (50 e $100 \mathrm{~g} \mathrm{ha}^{-1}$ ) e flumetsulam (70 e $140 \mathrm{~g} \mathrm{ha}^{-1}$ ), os quais foram seletivos para $B$. brizantha. Esses autores mencionaram ainda que o diuron, na dose de $1.600 \mathrm{~g} \mathrm{ha}^{-1}$, apresentou sintomas severos de fitointoxicação em estudo realizado em casa de vegetação.

Martins et al. (2007) verificaram que o herbicida imazethapyr (100 $\left.\mathrm{g} \mathrm{ha}^{-1}\right)$, aplicado em pós-emergência em $B$. brizantha, promoveu sintomas visuais leves de fitointoxicação, que não tiveram a altura e a massa seca reduzidas pela ação do herbicida.

Em relação à produção e à germinação de sementes de $B$. brizantha após a aplicação de herbicidas pré-emergentes (Tabela 3 ), verificou-se que a produção de sementes não foi afetada por nenhum dos herbicidas testados, apesar dos sintomas severos iniciais de fitointoxicação apresentados. Quanto à germinação de sementes, constatou-se que nenhum dos herbicidas promoveu redução na germinação, aumento da mortalidade de sementes, plântulas anormais e dormência de sementes de $B$. brizantha, além de não alterar a pureza. 
Tabela 1 - Fitointoxicação (\%) de B. brizantha após a aplicação de herbicidas pré-emergentes. BotucatuSP, 2007

\begin{tabular}{|c|c|c|c|c|c|}
\hline \multirow{2}{*}{ Tratamento } & \multirow{2}{*}{$\begin{array}{c}\text { Dose } \\
\left(\mathrm{g} \mathrm{ha}^{-1}\right)\end{array}$} & \multicolumn{4}{|c|}{ Data de avaliação ${ }^{1 /}$ (DAA) } \\
\hline & & 15 & 30 & 45 & 60 \\
\hline 1. diuron & 800 & $63,75 \mathrm{bc}$ & $52,50 \mathrm{bcd}$ & $35,00 \mathrm{ab}$ & $33,75 \mathrm{abc}$ \\
\hline 2. diuron & 1.600 & $90,00 \mathrm{a}$ & $83,50 \mathrm{a}$ & $59,75 \mathrm{a}$ & $50,00 \mathrm{a}$ \\
\hline 3. ametryn & 625 & $40,00 \mathrm{de}$ & $27,50 \mathrm{ef}$ & $16,25 \mathrm{bc}$ & $16,00 \mathrm{cde}$ \\
\hline 4. ametryn & 1.250 & $75,00 \mathrm{ab}$ & $72,50 \mathrm{ab}$ & $56,25 \mathrm{a}$ & $38,75 \mathrm{ab}$ \\
\hline 5. imazaquin & 75 & $18,75 \mathrm{efg}$ & $21,25 \mathrm{efg}$ & $20,00 \mathrm{cb}$ & $6,25 \mathrm{de}$ \\
\hline 6. imazaquin & 150 & $30,00 \mathrm{def}$ & 22,50 efg & $6,25 \mathrm{bc}$ & $5,00 \mathrm{de}$ \\
\hline 7. imazethapyr & 50 & $11,25 \mathrm{fg}$ & $5,00 \mathrm{fg}$ & $3,75 \mathrm{c}$ & $0,00 \mathrm{e}$ \\
\hline 8. imazethapyr & 100 & $47,50 \mathrm{~cd}$ & $41,25 \mathrm{cde}$ & $26,25 \mathrm{bc}$ & $17,50 \mathrm{cde}$ \\
\hline 9. flumetsulam & 70 & $47,50 \mathrm{~cd}$ & $33,75 \mathrm{de}$ & $22,50 \mathrm{bc}$ & $3,75 \mathrm{de}$ \\
\hline 10. flumetsulam & 140 & $73,75 \mathrm{ab}$ & $62,5 \mathrm{bc}$ & $40,00 \mathrm{ab}$ & $22,50 \mathrm{bcd}$ \\
\hline 11. testemunha & - & $0,00 \mathrm{~g}$ & $0,00 \mathrm{~g}$ & $0,00 \mathrm{~d}$ & $0,00 \mathrm{e}$ \\
\hline \multicolumn{2}{|c|}{$\mathrm{F}$ de tratamento } & $13,71 * *$ & $11,56^{* *}$ & $4,29 * *$ & $5,74 * *$ \\
\hline \multicolumn{2}{|c|}{$\mathrm{CV}(\%)$} & 34,23 & 41,30 & 74,58 & 80,60 \\
\hline \multicolumn{2}{|l|}{ d.m.s. } & 22,36 & 22,90 & 28,00 & 20,47 \\
\hline
\end{tabular}

${ }^{1 /}$ Fitointoxicação baseada na escala percentual e visual de notas de 0 a 100, na qual 0 consistiu em ausência de injúria e 100 em morte das plantas. ${ }^{*}$ Significativo a $1 \%$ de probabilidade. Médias seguidas da mesma letra na coluna não diferem estatisticamente entre si pelo teste $\mathrm{t}(\mathrm{P}>0,05)$. DAA - dias após a aplicação.

Tabela 2 - Altura $(\mathrm{cm})$ e produção de massa seca de plantas $(\mathrm{g}$ planta-1) de B. brizantha após a aplicação de herbicidas pré-emergentes. Botucatu-SP, 2007

\begin{tabular}{|c|c|c|c|c|c|c|}
\hline \multirow{2}{*}{ Tratamento } & \multirow{2}{*}{$\begin{array}{c}\text { Dose } \\
\left(\mathrm{g} \mathrm{ha}^{-1}\right)\end{array}$} & \multicolumn{4}{|c|}{ Data de avaliacão (DAA) } & \multirow{2}{*}{ M.S. ${ }^{1 /}$} \\
\hline & & 30 & 45 & 60 & 90 & \\
\hline 1. diuron & 800 & 17,34 bcde & 44,40 def & $61,47 \mathrm{def}$ & $163,12 \mathrm{a}$ & $1,89 \mathrm{abcd}$ \\
\hline 2. diuron & 1.600 & $14,29 \mathrm{e}$ & $38,42 \mathrm{f}$ & $50,82 \mathrm{f}$ & $146,00 \mathrm{~b}$ & $1,68 \mathrm{bcd}$ \\
\hline 3. ametryn & 625 & 14,72 bcd & 46,17 bcde & $65,35 \mathrm{cde}$ & $160,97 \mathrm{a}$ & $1,70 \mathrm{bcd}$ \\
\hline 4. ametryn & 1.250 & $15,29 \mathrm{cde}$ & $45,32 \mathrm{cdef}$ & 60,00 ef & $161,29 \mathrm{a}$ & $2,98 \mathrm{a}$ \\
\hline 5. imazaquin & 75 & $19,24 \mathrm{~b}$ & $51,66 \mathrm{bcd}$ & 69,82 bcde & $164,55 \mathrm{a}$ & $2,01 \mathrm{abcd}$ \\
\hline 6. imazaquin & 150 & $18,88 \mathrm{~b}$ & $51,63 \mathrm{bcd}$ & $71,47 \mathrm{bcd}$ & $162,79 \mathrm{a}$ & $1,50 \mathrm{~cd}$ \\
\hline 7. imazethapyr & 50 & $22,77 \mathrm{a}$ & $53,05 \mathrm{~b}$ & $76,92 \mathrm{ab}$ & $175,07 \mathrm{a}$ & $1,98 \mathrm{abcd}$ \\
\hline 8. imazethapyr & 100 & $17,99 \mathrm{bc}$ & $52,30 \mathrm{bc}$ & 70,37 bcde & $171,40 \mathrm{a}$ & $2,71 \mathrm{ab}$ \\
\hline 9. flumetsulam & 70 & $18,99 \mathrm{~b}$ & $50,00 \mathrm{bcd}$ & $73,22 \mathrm{abc}$ & $172,20 \mathrm{a}$ & $1,84 \mathrm{abcd}$ \\
\hline 10. flumetsulam & 140 & $14,74 \mathrm{de}$ & 39,88 ef & 59,68 ef & $164,24 \mathrm{a}$ & $0,95 \mathrm{~d}$ \\
\hline 11. testemunha & - & $24,14 \mathrm{a}$ & $61,99 \mathrm{a}$ & $82,65 \mathrm{a}$ & $169,59 \mathrm{a}$ & $2,23 \mathrm{abc}$ \\
\hline \multicolumn{2}{|c|}{$\mathrm{F}$ de tratamento } & $7,65^{* *}$ & $6,93 * *$ & $5,46^{* *}$ & $2,64^{*}$ & $1,97^{*}$ \\
\hline \multicolumn{2}{|c|}{$\mathrm{CV}(\%)$} & 12,18 & 10,45 & 11,47 & 5,79 & 40,48 \\
\hline \multicolumn{2}{|l|}{ d.m.s. } & 3,22 & 7,34 & 11,17 & 13,79 & 1,14 \\
\hline
\end{tabular}

** Significativo a $1 \%$ de probabilidade. ${ }^{*}$ Significativo a $5 \%$ de probabilidade. Médias seguidas da mesma letra na coluna não diferem estatisticamente entre si pelo teste $\mathrm{t}(\mathrm{P}>0,05)$. DAA - dias após a aplicação. ${ }^{1 /}$ Massa seca avaliada aos $45 \mathrm{DAA}$.

Na literatura consultada, verificou-se que os herbicidas imazethapyr $\left(100 \mathrm{~g} \mathrm{ha}^{-1}\right)$, chlorimuron-ethyl (15 $\left.\mathrm{g} \mathrm{ha}^{-1}\right)$, nicosulfuron a (50 $\mathrm{g} \mathrm{ha}^{-1}$ ) e bentazon (720 $\mathrm{g} \mathrm{ha}^{-1}$ ), aplicados em pós-emergência em $B$. brizantha, também não promoveram redução na produção e na germinação ou sobre a pureza de sementes, enquanto o atrazine (3.000 $\left.\mathrm{g} \mathrm{ha}^{-1}\right)$ promoveu redução na porcentagem de sementes normais (Martins et al., 2007).
Na Tabela 4 são apresentadas as médias de porcentagem de fitointoxicação de B. decumbens após a aplicação de herbicidas pré-emergentes. O imazaquin e flumetsulan, nas maiores doses, promoveram os maiores indices de fitointoxicação aos 15 DAA. As menores doses desses herbicidas e o imazethapyr (50 e $100 \mathrm{~g} \mathrm{ha}^{-1}$ ) promoveram fitointoxicação intermediária. Os herbicidas diuron e ametryn mostraram baixa fitointoxicação na forrageira. 
Tabela 3 - Efeito de herbicidas pré-emergentes na produção e na germinação de sementes de B. brizantha. Botucatu-SP, 2007

\begin{tabular}{|c|c|c|c|c|c|c|c|}
\hline \multirow[b]{2}{*}{ Tratamento } & \multirow{2}{*}{$\begin{array}{c}\text { Dose } \\
\left(\mathrm{g} \mathrm{ha}^{-1}\right)\end{array}$} & \multirow{2}{*}{$\begin{array}{c}\text { Produção }^{1 /} \\
\left(\mathrm{kg} \mathrm{ha}^{-1}\right)\end{array}$} & \multirow{2}{*}{$\begin{array}{c}\text { Pureza } \\
(\%)\end{array}$} & \multicolumn{4}{|c|}{ Teste de germinação } \\
\hline & & & & Normais $(\%)$ & $\begin{array}{c}\text { Anormais } \\
(\%)\end{array}$ & Mortas (\%) & $\begin{array}{c}\text { Dormentes } \\
(\%)\end{array}$ \\
\hline 1. diuron & 800 & 57,28 & 43,63 & 50,32 & 0,70 & 47,61 & 1,38 \\
\hline 2. diuron & 1.600 & 58,51 & 49,54 & 50,75 & 1,55 & 45,54 & 2,16 \\
\hline 3. ametryn & 625 & 53,70 & 31,81 & 55,70 & 0,76 & 41,56 & 1,96 \\
\hline 4. ametryn & 1.250 & 54,61 & 41,32 & 51,19 & 0,81 & 46,79 & 1,21 \\
\hline 5. imazaquin & 75 & 56,35 & 38,42 & 49,21 & 2,03 & 46,09 & 2,67 \\
\hline 6. imazaquin & 150 & 70,48 & 51,08 & 50,21 & 0,78 & 46,48 & 2,36 \\
\hline 7. imazethapyr & 50 & 82,46 & 51,42 & 48,18 & 0,82 & 48,12 & 2,88 \\
\hline 8. imazethapyr & 100 & 69,38 & 39,72 & 54,41 & 1,26 & 39,28 & 2,06 \\
\hline 9. flumetsulam & 70 & 63,86 & 42,75 & 57,12 & 0,96 & 38,81 & 3,12 \\
\hline 10. flumetsulam & 140 & 73,19 & 50,64 & 46,05 & 0,96 & 49,55 & 3,44 \\
\hline 11. testemunha & - & 55,98 & 41,03 & 56,37 & 1,54 & 41,19 & 0,90 \\
\hline \multicolumn{2}{|c|}{$\mathrm{F}$ tratamento } & $0,43^{\mathrm{ns}}$ & $0,56^{\mathrm{ns}}$ & $0,95^{\mathrm{ns}}$ & $1,36^{\mathrm{ns}}$ & $0,84^{\mathrm{ns}}$ & $1,73^{\mathrm{ns}}$ \\
\hline \multicolumn{2}{|l|}{$\mathrm{CV}(\%)$} & 45,27 & 38,47 & 15,43 & 67,10 & 18,33 & 55,90 \\
\hline \multicolumn{2}{|l|}{ d.m.s. } & 69,93 & 41,11 & 19,62 & 1,81 & 19,98 & 2,99 \\
\hline
\end{tabular}

ns Não significativo. ${ }^{1 /}$ Sementes puras.

Tabela 4 - Fitointoxicação (\%) de B. decumbens após a aplicação de herbicidas pré-emergentes. Botucatu-SP, 2007

\begin{tabular}{|c|c|c|c|c|c|}
\hline \multirow{2}{*}{ Tratamento } & \multirow{2}{*}{$\begin{array}{c}\text { Dose } \\
\left(\mathrm{g} \mathrm{ha}^{-1}\right)\end{array}$} & \multicolumn{4}{|c|}{ Data de avaliação $1 /$ (DAA) } \\
\hline & & 15 & 30 & 45 & 60 \\
\hline 1. diuron & 800 & $10,00 \mathrm{de}$ & $10,00 \mathrm{de}$ & $8,75 \mathrm{de}$ & $1,25 \mathrm{de}$ \\
\hline 2. diuron & 1.600 & $15,00 \mathrm{cde}$ & $28,75 \mathrm{~cd}$ & $28,75 \mathrm{~cd}$ & $21,25 \mathrm{cde}$ \\
\hline 3. ametryn & 625 & $3,75 \mathrm{e}$ & $2,50 \mathrm{e}$ & $2,50 \mathrm{e}$ & $0,00 \mathrm{e}$ \\
\hline 4. ametryn & 1.250 & $16,25 \mathrm{cde}$ & $36,25 \mathrm{bc}$ & $31,25 \mathrm{~cd}$ & $20,00 \mathrm{cde}$ \\
\hline 5. imazaquin & 75 & $38,75 \mathrm{~b}$ & $51,25 \mathrm{~b}$ & $41,25 \mathrm{bc}$ & $38,75 \mathrm{bc}$ \\
\hline 6. imazaquin & 150 & $65,00 \mathrm{a}$ & $76,25 \mathrm{a}$ & $56,25 \mathrm{~b}$ & $50,00 \mathrm{ab}$ \\
\hline 7. imazethapyr & 50 & $27,50 \mathrm{bcd}$ & $21,25 \mathrm{cde}$ & $21,25 \mathrm{cde}$ & $0,00 \mathrm{e}$ \\
\hline 8. imazethapyr & 100 & $33,75 \mathrm{bc}$ & $27,50 \mathrm{~cd}$ & 21,25 bce & $15,50 \mathrm{cde}$ \\
\hline 9. flumetsulam & 70 & 28,75 bcd & $32,50 \mathrm{bc}$ & $33,75 \mathrm{bc}$ & $27,50 \mathrm{bcd}$ \\
\hline 10. flumetsulam & 140 & $67,50 \mathrm{a}$ & $92,50 \mathrm{a}$ & $92,00 \mathrm{a}$ & $76,25 \mathrm{a}$ \\
\hline 11. testemunha & - & $0,00 \mathrm{e}$ & $0,00 \mathrm{e}$ & $0,00 \mathrm{e}$ & $0,00 \mathrm{e}$ \\
\hline \multicolumn{2}{|c|}{$\mathrm{F}$ de tratamento } & $10,44 * *$ & $14,18 * *$ & $8,31 * *$ & $10,40 * *$ \\
\hline \multicolumn{2}{|c|}{$\mathrm{CV}(\%)$} & 27,84 & 44,88 & 54,53 & 53,32 \\
\hline \multicolumn{2}{|l|}{ d.m.s. } & 20,15 & 22,32 & 25,64 & 23,59 \\
\hline
\end{tabular}

1/ Fitointoxicação baseada na escala percentual e visual de notas de 0 a 100 , na qual 0 consistiu em ausência de injúria e 100 em morte das plantas. ${ }^{*}$ Significativo a $1 \%$ de probabilidade. Médias seguidas da mesma letra na coluna não diferem estatisticamente entre si pelo teste $\mathrm{t}(\mathrm{P}>0,05)$. DAA - dias após a aplicação.

As plantas apresentaram leve redução dos sintomas de injúrias a partir dos 30 DAA, semelhante ao observado para $B$. brizantha, sendo que os herbicidas diuron, ametryn e imazethapyr, independentemente da dose utilizada, promoveram sintomas de fitointoxicação inferiores a $21,25 \%$, aos
60 DAA. No entanto, apenas o imazaquin (75 e $150 \mathrm{~g} \mathrm{ha}^{-1}$ ) e o flumetsulam (70 e $140 \mathrm{~g} \mathrm{ha}^{-1}$ ) diferiram da testemunha sem aplicação.

As médias de altura e de produção de massa seca das plantas de $B$. decumbens após a aplicação dos herbicidas pré-emergentes são 
apresentadas na Tabela 5. Os herbicidas mostraram redução na altura de plantas aos 30 DAA, com exceção do ametryn (625 $\left.\mathrm{g} \mathrm{ha}^{-1}\right)$. Contudo, aos 90 DAA, nenhum dos herbicidas avaliados diferiu da testemunha sem aplicação.

Os herbicidas imazaquin e flumetsulam, na menor dose, proporcionaram reduções na massa seca da forrageira em torno de 64,17 e $54,55 \%$ em relação à testemunha, respectivamente, ao passo que para a maior dose a redução foi de 49,20 e 76,47\%, respectivamente, aos 45 DAA. Os demais herbicidas, mesmo proporcionando elevados niveis iniciais de injúrias, não influenciaram negativamente o acúmulo de massa seca das plantas de B. decumbens (Tabela 5).

Alves et al. (2002) constataram que os herbicidas imazaquin (75 e $\left.150 \mathrm{~g} \mathrm{ha}^{-1}\right)$, imazethapyr (50 e $\left.100 \mathrm{~g} \mathrm{ha}^{-1}\right)$ e ametryn $\left(625 \mathrm{~g} \mathrm{ha}^{-1}\right)$ foram seletivos para a B. decumbens. Da mesma forma, Martins et al. (2007) verificaram que o herbicida imazethapyr (100 $\mathrm{g} \mathrm{ha}^{-1}$ ), aplicado em pós-emergência em $B$. decumbens, promoveu sintomas visuais leves, bem como não reduziu a altura e a massa seca das plantas.

Trigueiro et al. (2007) verificaram, em Panicum maximum cv. Mombaça, que o herbicida ametryn ( $\left.1.250 \mathrm{~g} \mathrm{ha}^{-1}\right)$, aplicado em pós-emergência, reduziu a produção de sementes, mas não afetou a germinação, enquanto, para o cultivar Tanzânia, o ametryn $\left(1.250 \mathrm{~g} \mathrm{ha}^{-1}\right)$ foi seletivo e não afetou a produção e a qualidade fisiológica das sementes.

Na Tabela 6 estão demonstradas as médias de produção e germinação de sementes de $B$. decumbens após a aplicação de herbicidas pré-emergentes. Verificou-se que a produção de sementes não foi alterada por nenhum dos herbicidas testados. Quanto à germinação de sementes, notou-se que nenhum dos herbicidas promoveu redução na porcentagem de germinação, aumento da mortalidade de sementes, aumento na porcentagem de plântulas anormais e aumento de sementes dormentes, além de não terem alterado a pureza.

Com base nos resultados, pode-se concluir que os herbicidas apresentaram algum efeito fitotóxico sobre as gramíneas forrageiras avaliadas. Os herbicidas ametryn (625 $\left.\mathrm{g} \mathrm{ha}^{-1}\right)$, imazaquin (75 e $\left.150 \mathrm{~g} \mathrm{ha}^{-1}\right)$, imazethapyr (50 e $\left.100 \mathrm{~g} \mathrm{ha}^{-1}\right)$ e flumetsulam $\left(70\right.$ e $\left.140 \mathrm{~g} \mathrm{ha}^{-1}\right)$ foram os que proporcionaram maior seletividade às plantas de $B$. brizantha; para B. decumbens, diuron (800 e $\left.1.600 \mathrm{~g} \mathrm{ha}^{-1}\right)$, ametryn (625 e $\left.1.250 \mathrm{~g}^{\text {ha }}{ }^{1}\right)$ e imazethapyr

Tabela 5 - Altura $(\mathrm{cm})$ e produção de massa seca de plantas $\left(\mathrm{g}\right.$ planta $\left.^{-1}\right)$ de B. decumbens após a aplicação de herbicidas préemergentes. Botucatu-SP, 2007

\begin{tabular}{|c|c|c|c|c|c|c|}
\hline \multirow[t]{2}{*}{ Tratamento } & \multirow{2}{*}{$\begin{array}{c}\text { Dose } \\
\left(\mathrm{g} \mathrm{ha}^{-1}\right)\end{array}$} & \multicolumn{4}{|c|}{$\begin{array}{c}\text { Data de avaliação } \\
\text { (DAA) }\end{array}$} & \multirow[t]{2}{*}{ M.S. ${ }^{1 /}$} \\
\hline & & 30 & 45 & 60 & 90 & \\
\hline 1. diuron & 800 & $17,50 \mathrm{bc}$ & $49,84 \mathrm{abc}$ & $82,07 \mathrm{ab}$ & 105,87 & $1,47 \mathrm{abc}$ \\
\hline 2. diuron & 1.600 & $14,09 \mathrm{~cd}$ & 41,17 cde & $67,16 \mathrm{de}$ & 107,37 & $1,03 \mathrm{abcd}$ \\
\hline 3. ametryn & 625 & $20,86 \mathrm{ab}$ & $55,33 \mathrm{a}$ & $85,90 \mathrm{a}$ & 108,20 & $1,40 \mathrm{abc}$ \\
\hline 4. ametryn & 1.250 & $14,24 \mathrm{~cd}$ & 42,31 bcde & 71,84 bcde & 109,17 & $1,33 \mathrm{abc}$ \\
\hline 5. imazaquin & 75 & 10,04 ef & $35,88 \mathrm{de}$ & $64,64 \mathrm{de}$ & 108,43 & $0,67 \mathrm{~cd}$ \\
\hline 6. imazaquin & 150 & $10,36 \mathrm{ef}$ & $32,56 \mathrm{ef}$ & 61,03 ef & 110,18 & $0,95 \mathrm{bcd}$ \\
\hline 7. imazethapyr & 50 & $16,02 \mathrm{~cd}$ & $45,58 \mathrm{abcd}$ & $76,60 \mathrm{abcd}$ & 110,08 & $1,79 \mathrm{ab}$ \\
\hline 8. imazethapyr & 100 & $14,05 \mathrm{~cd}$ & $51,61 \mathrm{abc}$ & 72,79 bcde & 108,22 & $1,15 \mathrm{abcd}$ \\
\hline 9. flumetsulam & 70 & $13,33 \mathrm{de}$ & $41,55 \mathrm{cde}$ & 69,77 cde & 105,27 & $0,85 \mathrm{~cd}$ \\
\hline 10. flumetsulam & 140 & $6,75 \mathrm{f}$ & $24,74 \mathrm{f}$ & $49,60 \mathrm{f}$ & 106,70 & $0,44 \mathrm{~d}$ \\
\hline 11. testemunha & - & $21,55 \mathrm{a}$ & $52,80 \mathrm{ab}$ & $80,98 \mathrm{abc}$ & 108,24 & $1,87 \mathrm{a}$ \\
\hline \multicolumn{2}{|c|}{$\mathrm{F}$ de tratamento } & $12,67 * *$ & $6,38^{* *}$ & $6,34^{* *}$ & $0,77^{\mathrm{ns}}$ & $2,07 *$ \\
\hline \multicolumn{2}{|c|}{$\mathrm{CV}(\%)$} & 17,42 & 10,69 & 11,68 & 3,33 & 50,00 \\
\hline \multicolumn{2}{|l|}{ d.m.s. } & 3,63 & 3,70 & 12,00 & 5,19 & 0,87 \\
\hline
\end{tabular}

** Significativo a $1 \%$ de probabilidade. ${ }^{*}$ Significativo a $5 \%$ de probabilidade. ${ }^{n s}$ Não significativo. Médias seguidas da mesma letra na coluna não diferem estatisticamente entre si pelo teste $\mathrm{t}(\mathrm{P}>0,05)$. DAA - dias após a aplicação. ${ }^{11}$ Massa seca avaliada aos 45 DAA. 
Tabela 6 - Efeito de herbicidas pré-emergentes na produção e germinação de sementes de B. decumbens. Botucatu-SP, 2007

\begin{tabular}{|c|c|c|c|c|c|c|c|}
\hline \multirow{2}{*}{ Tratamento } & \multirow{2}{*}{$\begin{array}{c}\text { Dose } \\
\left(\mathrm{g} \mathrm{ha}^{-1}\right)\end{array}$} & \multirow{2}{*}{$\begin{array}{c}\text { Produção }^{1 /} \\
\left(\mathrm{kg} \mathrm{ha}^{-1}\right)\end{array}$} & \multirow{2}{*}{$\begin{array}{c}\text { Pureza } \\
(\%)\end{array}$} & \multicolumn{4}{|c|}{ Teste de germinação (\%) } \\
\hline & & & & Normais & Anormais & Mortas & Dormentes \\
\hline 1. diuron & 800 & 115,67 & 57,23 & 77,01 & 1,74 & 21,05 & 0,20 \\
\hline 2. diuron & 1.600 & 117,56 & 60,24 & 74,17 & 1,50 & 24,27 & 0,06 \\
\hline 3. ametryn & 625 & 116,41 & 54,57 & 71,10 & 1,70 & 27,00 & 0,19 \\
\hline 4. ametryn & 1.250 & 102,55 & 61,34 & 75,56 & 2,22 & 22,03 & 0,19 \\
\hline 5. imazaquin & 75 & 90,21 & 43,29 & 71,02 & 1,63 & 27,22 & 0,12 \\
\hline 6. imazaquin & 150 & 89,14 & 46,18 & 75,97 & 2,00 & 21,97 & 0,06 \\
\hline 7. imazethapyr & 50 & 116,00 & 70,26 & 73,08 & 2,00 & 24,79 & 0,12 \\
\hline 8. imazethapyr & 100 & 117,21 & 69,09 & 72,99 & 2,19 & 24,69 & 0,13 \\
\hline 9. flumetsulam & 70 & 92,26 & 53,15 & 75,52 & 1,81 & 22,54 & 0,12 \\
\hline 10. flumetsulam & 140 & 71,57 & 47,84 & 78,98 & 1,25 & 19,76 & 0,00 \\
\hline 11. testemunha & - & 91,31 & 38,38 & 74,22 & 1,56 & 24,03 & 0,19 \\
\hline \multicolumn{2}{|c|}{$\mathrm{F}$ tratamento } & $1,34^{\mathrm{ns}}$ & $1,61^{\mathrm{ns}}$ & $1,93^{\mathrm{ns}}$ & $0,80^{\mathrm{ns}}$ & $2,06^{\mathrm{ns}}$ & $1,10^{\mathrm{ns}}$ \\
\hline \multicolumn{2}{|c|}{ CV $(\%)$} & 26,83 & 29,51 & 4,69 & 37,47 & 13,93 & 95,24 \\
\hline \multicolumn{2}{|l|}{ d.m.s } & 66,70 & 39,41 & 8,53 & 1,63 & 8,02 & 0,17 \\
\hline
\end{tabular}

${ }^{\text {ns }}$ Não significativo. ${ }^{1 /}$ Sementes puras.

(50 e $100 \mathrm{~g} \mathrm{ha}^{-1}$ ) foram mais seletivos, destacando-se o primeiro na menor dose. No entanto, os efeitos prejudiciais dos herbicidas observados na fase vegetativa não afetaram a produção e a qualidade das sementes das forrageiras $B$. brizantha e $B$. decumbens.

\section{LITERATURA CITADA}

ALVES, E.; MARTINS, D.; SOUZA, F. H. D. Seletividade de herbicidas pré-emergentes para gramíneas forrageiras tropicais. Planta Daninha, v. 20, n. 3, p. 457-464, 2002.

BORGHI, E. et al. Influência da distribuição espacial do milho e da Brachiaria brizantha consorciados sobre a população de plantas daninhas em sistema plantio direto na palha.

Planta Daninha, v. 26, n.3, p. 559-568, 2008.

BRASIL. Ministério da Agricultura e Reforma Agrária. Regras para análise de sementes. Brasília: SNDA/DNDV/ CLV, 1992. 365 p.

DIAS, M. C. L. L.; ALVES, S. J. Avaliação da viabilidade de sementes de Brachiaria brizantha (Hochst. Ex A. Rich) Stapf pelo teste de tetrazólio. In: CONGRESSO BRASILEIRO DE SEMENTES, 12., 2001, Curitiba. Anais.... Londrina: 2001. Inf. Abrates, v. 11, n. 2, p. 317, 2001

FERRI, M. V. W.; ELTZ, F. L. F.; LOPES, S. J. Aplicação de herbicidas dessecantes em pastagens nativas constituídas por differentes espécies do gênero paspalum. Ci. Rural, v. 31, n. 4, p. 589-595, 2001
GASPAR, C. M. et al. Alternativas para a manutenção da umidade do substrato durante o teste de germinação de Brachiaria brizantha. In: CONGRESSO BRASILEIRO DE SEMENTES, 13., 2003, Gramado. Anais... Londrina: 2003. Inf. Abrates, v. 13, n. 3, p. 171, 2003.

JAKELAITIS, A. et al. Manejo de plantas daninhas no consórcio de milho com capim-braquiária (Brachiaria decumbens). Planta Daninha, v. 22, n. 4, p. 553-560, 2004

FONTOURA JÚNIOR, J. A. S. et al. Produção animal em pastagem nativa submetida ao controle de plantas indesejáveis e a intensidades de pastejo. Ci. Rural, v. 37, n. 1, p. 247-252, 2007.

LOCH, D. S. L.; HARVEY, G. L. Developing herbicide strategies for tropical herbage seed crops. In: AUSTRALIAN NEW CROPS CONFERENCE, 1., 1996, Queensland.

Proceedings... Queensland: Gaton College, 1997. p. 273-282.

MARTINS, D. et al. Seletividade de herbicidas aplicados em pós-emergência sobre capim-braquiária. R. Bras. Zootec., v. 36, n. 6, p. 1969-1974, 2007.

PELLEGRINI, L. G. et al. Diferentes métodos de controle de plantas indesejáveis em pastagem nativa. R. Bras. Zootec., v. 36, n. 5 , p. 1247-1254, 2007.

PELLEGRINI, L. G. et al. Produção de forragem e dinâmica de uma pastagem natural submetida a diferentes métodos de controle de espécies indesejáveis e à adubação. R. Bras.

Zootec., v. 39, n. 11, p. 2380-2388, 2010 
PEREIRA, F. A. R.; ORNELAS, A. J.; HIDALGO, E. Avaliação do herbicida metsulfuronmethyl no controle de plantas daninhas em área de produção de sementes de pastagens. R. Bras. Herbic., v. 1, n. 2, p. 179-183, 2000 .

RAIJ, B. van et al. Recomendações de adubação e calagem para o estado de São Paulo. Campinas: 1997. 285 p. (Boletim Técnico, 100)
SOCIEDADE BRASILEIRA DA CIÊNCIA DAS PLANTAS DANINHAS - SBPD. Procedimentos para instalação, avaliação e análise de experimentos com herbicidas. Londrina: $1995.42 \mathrm{p}$.

TRIGUEIRO, L. R. C. et al. Seletividade de herbicidas aplicados em pós-emergência sobre capim-colonião e efeito na qualidade das sementes. Planta Daninha, v. 25, n. 2, p. 341-349, 2007. 